\title{
Does Electoral Competition Curb Party Favoritism?
}

\author{
By Marta Curto-Grau, Albert Solé-Ollé, and Pilar Sorribas-Navarro*
}

We study whether incumbents facing uncontested elections channel public spending toward co-partisan officials more than is the case of incumbents that are worried about reelection. We draw on data on capital transfers allocated by Spanish regions to local governments during 1995-2007. Using a regression discontinuity design, we document strong and robust effects. We find that a mayor belonging to the party of the regional president obtains twice the amount in grants received by an opposition's mayor. This effect is much greater for regional incumbents that won the previous election by a large margin, but it disappears for highly competitive elections. (JEL D72, H76)

Dolitical favoritism describes situations in which politicians "allocate goods and services disproportionately to population subgroups, variably identifiable by race, ethnicity, or partisanship" (Golden and Min 2013, 74). Jointly with corruption, political favoritism constitutes a major political risk of government intervention (Glaeser 2012). Because of political favoritism, spending allocations deviate from the normative principles that should otherwise guide them, reducing citizen welfare and hampering economic growth. 1 Likewise, party favoritism describes situations in which officials affiliated to the incumbent party are able to attract disproportionate benefits from the public budget. Representatives of the majority party in parliament might obtain more local public goods for their districts, while co-partisan mayors might receive more intergovernmental transfers. In all these cases, "... hierarchical networks of party officials (factions) work to direct local public goods to their constituencies and thereby win votes and advance their careers within the party" (Persico, Pueblita, and Silverman 2011, 242). In other words, lower level politicians obtain more resources from a fellow, higher level party official because

\footnotetext{
* Curto-Grau: School of Economics, Universitat de Barcelona, Carrer John M. Keynes, 1-11, Barcelona, 08034 (email: mcurto@ub.edu); Solé-Ollé: School of Economics, Universitat de Barcelona, Carrer John M. Keynes, 1-11, Barcelona 08034 (email: asole@ub.edu); Sorribas-Navarro: School of Economics, Universitat de Barcelona, Carrer John M. Keynes, 1-11, Barcelona 08034 (email: psorribas@ub.edu). We are grateful to the two anonymous referees and participants in numerous seminars and conferences for their helpful comments. We also thank Dan Bogart, Fernanda Brollo, Jan Brueckner, Ronny Freier, Olle Folke, Ami Glazer, Henrik Jordhal, Humberto Llavador, Tommasso Nannicini, Joaquin Naval, Torsten Persson, Nadine Riedel, Jonathan Rodden, and Galina Zudenkova for insightful comments. This research has received funding from projects ECO2015-68311-R (Ministerio de Educación y Ciencia) and 2014SGR420 (Generalitat de Catalunya).

Go to https://doi.org/10.1257/app.20160618 to visit the article page for additional materials and author disclosure statement(s) or to comment in the online discussion forum.

${ }^{1}$ For example, ethnic favoritism has been identified as a major impediment to development in Africa (Easterly and Levine 1997). Other authors have documented the negative effect of favoritism on aid effectiveness (Dreher et al. 2013) and on stimulus spending (Wright 1974).
} 
they are expected to help her retain office, and they are happy to provide support at election time as they too have expectations of future promotion.

But how can political favoritism be curbed? It is an old assumption that governments are held accountable to the citizens through the electoral process. An incumbent's desire for reelection should ensure that she does not deviate from the constituents' interests and focus on a too narrow segment of the population. However, this only holds true if certain conditions are met. For example, Hodler and Raschky (2014) show that regional favoritism (i.e., the tendency to benefit the political leader's region of birth) is stronger in countries with weak political institutions and low education levels. There is also some evidence that information and political participation help curb ethnic favoritism (see Fujiwara and Wantchekon 2013). And, more importantly as far as this paper is concerned, several studies suggest that political favoritism flourishes when there are no elections or when elections are uncompetitive. Clear evidence of this is provided by Burgess et al. (2015), who show that ethnic favoritism, as reflected in expenditure on road building in Kenya, was high in autocratic periods, but disappeared in periods with free elections. Similarly, Trounstine (2006) shows that US city mayors facing uncontested elections tend to target core supporters at the expense of the larger community when allocating public spending.

In this paper, we examine the effects of electoral competition on party favoritism when allocating earmarked capital transfers to local governments. We consider this setting to be highly suited to the study of party favoritism and its relation to electoral competition for several reasons. First, intergovernmental transfers of this kind are especially vulnerable to party favoritism. These transfers provide funds that have to be spent in a very limited range of areas as determined by the grantor. Second, these transfers fund services that are the joint responsibility of two layers of government. This means that voters have to split any political credit for the service or facility financed between two incumbents. When a co-partisan (the opposition) controls the local government, a transfer enhances (reduces) the popularity of the mayor, while reducing (enhancing) that of the opposition candidate (see e.g., Arulampalam et al. 2009). This suggests that intergovernmental transfers can be used to help co-partisan mayors win competitive races. Third, incentives to engage in party favoritism can also depend on how close the higher level election race is. When the higher tier incumbent is at risk of losing an immediate election, we can expect her to focus on strategies that are more productive in the short run, such as targeting constituencies with many swing voters. ${ }^{2}$

The goal of this paper, therefore, is to determine whether the amount of party favoritism shown in the allocation of transfers to local governments is not so great when the higher layer government (i.e., the grantor) faces contested elections. We present a simple theoretical model that predicts this heterogeneous effect. In the model, a higher level incumbent allocates transfers to local governments with the aim of maximizing her probability of staying in power. The incumbent has to decide

\footnotetext{
${ }^{2}$ The literature on pork barrel politics has traditionally focused on other tactics, namely, the targeting of spending to either "swing" (e.g., Lindbeck and Weibull 1987, and Dixit and Londregan 1996) or "core" supporter districts (e.g., Cox and McCubbins 1986).
} 
whether to allocate more transfers to co-partisan mayors facing close elections (and, thus, increase the pool of aligned mayors) or to spread the money across all districts in order to maximize her probability of reelection. When higher level elections are uncompetitive, the incumbent uses her advantage to pursue the first objective. ${ }^{3}$

We test these predictions using information on capital transfers from regional to local governments in Spain. Several papers to date have documented the fact that party favoritism in the allocation of intergovernmental transfers is quantitatively important. Using US data, Grossman (1994); Larcinese, Rizzo, and Testa (2006); and Berry, Burden, and Howell (2010) find some evidence that states and districts aligned with the federal government do receive more funds. Arulampalam et al. (2009) quantify this difference as representing 16 percent in the case of federal-to-regional transfers in India. Diaz-Cayeros, Magaloni, and Weingast (2003) find, in the case of Mexico, that under the PRI, the states controlled by this party received up to 40 percent more transfers than those controlled by the opposition. Similarly, Solé-Ollé and Sorribas-Navarro (2008) and Brollo and Nannicini (2012) look at capital transfers to municipalities and report increases of around 30 and 40 percent for Spain and Brazil, respectively.

However, none of these papers studies the effect of the competitiveness of higher level elections nor do they provide any evidence as to why a given degree of party favoritism is observed. ${ }^{4}$ One reason for this might be that these papers use data for a single high-tier government (usually the federal government during one or a few elections), making it impossible to estimate heterogeneous effects. In this paper, we make use of a newly compiled database on transfers from Spanish regional governments (the so-called Autonomous Communities, ACs from now on) during three terms of office for more than 2,000 Spanish municipalities. Thus, we can analyze whether party favoritism depends on certain characteristics of the ACs and, in particular, we are able to test the hypothesis that the probability of the regional incumbent losing office does genuinely matter. Spain is particularly well-suited to studying this question given that there is substantial variability in the intensity of electoral competition at the regional level, both in the cross section and over time.

In order to identify the effect of party favoritism, we use a regression discontinuity (RD) design for close elections, comparing municipalities in which the ideological bloc of the regional incumbent won or lost the previous local election by a narrow margin. The effects estimated in some of the aforementioned papers (employing either OLS or "difference-in-differences" methods) might be biased due to the omission of time-varying electoral support for the incumbent. Brollo and Nannicini (2012), Migueis (2013), and Bracco et al. (2015) improve on this by using RD, as is now customary in papers examining the effects of parties on policy outcomes (see, e.g., Lee, Moretti, and Butler 2004; Pettersson-Lidbom 2008; Ferreira and Gyourko 2009; and Meyersson 2014). Employing a RD design in a PR system is challenging,

\footnotetext{
${ }^{3}$ A similar dynamic trade-off is modeled in Joanis (2011). In that paper the incumbent decides whether to target "swing" voter districts to win the present election or "core" voter districts to keep loyal voters motivated.

${ }^{4}$ Likewise, only a few papers examine the effect of electoral competitiveness on pork barrel politics. Ansolabehere and Snyder (2006) analyze whether the tendency to favor "core" over "swing" districts in the United States is mediated by state-level electoral competition, but find no evidence of this. In addition, Joanis (2011) looks at the effects of electoral competition on the allocation of revenues for roads in Canada and finds no effect.
} 
but a number of recent studies have clearly established the steps to follow (see Folke 2014, for the seminal paper, and also Ade and Freier 2013; Fiva and Halse 2016; and Fiva, Folke, and Sørensen 2018). We adapt this methodology to the Spanish context. We follow these papers and define our treatment (i.e., alignment) as a situation in which the ideological bloc to which the regional president belongs has a majority of seats in the local council. We use a forcing variable based on a calculation of the votes that the regional president's bloc must lose (gain) at the local election in order to lose (gain) the majority of seats on the council.

What we find is striking. The RD estimates suggest that Spanish local governments controlled by the same party as the regional government receive, on average, 102 percent more funds for capital transfers than are received by similar municipalities controlled by the opposition. These results represent unequivocal evidence of an extreme degree of party favoritism in the allocation of capital transfers. The alignment effect found means that, on average, municipalities could increase their capital spending by 21 percent. More importantly, the competitiveness of regional-level elections influences these biases in the allocation of transfers. According to our results, the level of party favoritism for the regions with less competitive elections is much higher (nearly twice the average treatment effect), while the treatment effect virtually disappears in the case of the more competitive regional elections. This effect survives many robustness checks and alternative specifications. Moreover, although a simple "difference-in-differences" estimator delivers lower average treatment effects, the relative effect of regional electoral competitiveness remains. Therefore, our results provide strong evidence that electoral competition at the regional level mitigates the degree of party favoritism in the allocation of intergovernmental transfers.

The paper is organized as follows. In the next section, we present a simple theoretical model that generates the prediction that party favoritism is greater when regional elections are uncompetitive. Section II provides the institutional background to the Spanish case. Section III describes the empirical methodology. Section IV presents the results and the last section concludes.

\section{Theoretical Framework}

In this section, we present a theoretical model that helps us derive our main hypothesis: when the regional incumbent perceives a higher probability of losing office (i.e., electoral competition is high), the degree of party favoritism in the allocation of transfers is lower. The reason our model makes this prediction is that, when allocating transfers across local municipalities, the regional incumbent faces a tradeoff between trying to win the current regional-level election and maximizing the number of aligned mayors. To maximize her probability of winning the regional election, the incumbent must spread transfers across all municipalities, while to maximize the number of mayors she must concentrate on those with a narrow majority, favoring co-partisan mayors and undermining those of the opposition. When regional elections are highly competitive, the regional incumbent allocates transfers without discrimination, with the aim of maximizing her vote. However, when the regional incumbent feels safe, she can forget about having to win more aggregate 
votes and can focus on seeking to switch the outcome in those municipalities where the opposition has a narrow majority.

Model Layout.-The model comprises two tiers of government: regional and local. We assume there is one regional government and $N$ local governments. Citizens cast their vote separately at local and regional elections that take place simultaneously on time. They select the party to rule at each tier by choosing between two candidates. At both contests, voters decide whether to reelect the incumbent (i.e., the regional president or the mayor, depending on the election) or to replace her with the challenger. In making such decisions, voters take into account the utility derived from transfers allocated from the regional to the local government. Per capita transfers to local government $i$ are denoted by $\tau_{i}$, the voter's utility function $u\left(\tau_{i}\right)$ is assumed to be concave (i.e., $u^{\prime}>0$ and $u^{\prime \prime}<0$ ) and the marginal utility is assumed to be linear (i.e., $\left.u^{\prime \prime \prime}=0\right)$.

Voters split the credit from transfer-related utility between the regional and the local incumbent in proportions $(1-\theta)$ and $\theta$, respectively (see Arulampalam et al. 2009), with $0 \leq \theta \leq 1$. The vote for the regional incumbent's party at these two elections in municipality $i$ can be expressed as follows:

$$
\begin{aligned}
& v_{i}^{r, 1}=\rho^{r} v_{i}^{r, 0}+(1-\theta) u\left(\tau_{i}\right)+\varepsilon_{i}^{r}, \\
& v_{i}^{\ell, 1}=\rho^{\ell} v_{i}^{\ell, 0}+\theta\left(2 a_{i}-1\right) u\left(\tau_{i}\right)+\varepsilon_{i}^{\ell},
\end{aligned}
$$

where $v_{i}^{r, 1}$ and $v_{i}^{r, 0}$ are the vote margin (i.e., the vote share minus one-half) obtained by the regional incumbent's party in municipality $i$ at the regional elections (denoted by $r$ ) held in periods 1 (the next election) and 0 (the previous election); and $v_{i}^{\ell, 1}$ and $v_{i}^{\ell, 0}$ are the vote margin obtained by the regional incumbent's party in municipality $i$ at the local elections (denoted by $\ell$ ) held also in periods 1 and 0 . The coefficients $\rho^{r}$ and $\rho^{\ell}$ measure the degree of persistence of vote decisions. The terms $\varepsilon_{i}^{r}$ and $\varepsilon_{i}^{\ell}$ are random popularity shocks at the regional and local elections, respectively, distributed $N\left(0, \sigma_{r}\right)$ and $N\left(0, \sigma_{\ell}\right)$, which are assumed to be independent of each other.

The term $(1-\theta) u\left(\tau_{i}\right)$ in equation (1a) captures the effect of transfers on the vote for the regional incumbent at the regional elections: voters are willing to reward the regional incumbent in exchange for the utility derived from the transfers she allocated to the municipality, in proportion to the responsibility for the quality of the service attributed to the regional government, measured by $(1-\theta)$. The term $\theta\left(2 a_{i}-1\right) u\left(\tau_{i}\right)$ in equation (1b) captures the effect of transfers on the vote for the candidate of the regional incumbent at the local elections. Note that now the transfer-derived utility is multiplied by the term $\theta\left(2 a_{i}-1\right)$, which depends on the proportion of responsibility attributed to the local government, $\theta$, but also on whether the local and the regional incumbent belong to the same party (i.e., $a_{i}=1$ ) or to different parties (i.e., $a_{i}=0$ ). For a mayor belonging to the regional incumbent's party, the effect of transfers on the vote at local elections is $\theta u\left(\tau_{i}\right)$, whereas when the mayor belongs to the regional opposition party the effect of transfers is $-\theta u\left(\tau_{i}\right)$. For the regional incumbent, assigning transfers to a local government 
controlled by the opposition will harm the vote record of the opposition candidate at the local elections.

We consider that a regional incumbent might pursue two goals. First, she might seek to maximize the probability of winning the current regional election. Second, she might want to maximize the number of aligned mayors, with the purpose of building political capital and increasing the chances of winning future regional elections. An objective function combining these two goals can be expressed as

$$
\begin{aligned}
\max _{\tau_{i}}\left\{\operatorname{Pr}\left(\sum_{i} \rho^{r} v_{i}^{r, 0}+(1-\theta) u\left(\tau_{i}\right)>\varepsilon_{i}^{r}\right)\right. \\
\left.\quad+\eta \sum_{i} \operatorname{Pr}\left(\rho^{\ell} v_{i}^{\ell, 0}+\theta\left(2 a_{i}-1\right) u\left(\tau_{i}\right)>\varepsilon_{i}^{\ell}\right)-c\left(\sum_{i} \tau_{i}\right)\right\} .
\end{aligned}
$$

The first part of this expression is the probability of wining the current regional election, which depends on the summation of votes across municipalities. The second part is the number of mayors belonging to the regional incumbent's party, which depends on the summation of the probabilities of winning each local election. The parameter $\eta$ is a coefficient that depends both on the amount of political capital provided by mayors (i.e., how crucial it is to have the mayors' support during future regional-level campaigns) and on a discount factor (i.e., how important are future versus current regional elections). The term $c\left(\sum_{i} \tau_{i}\right)$ is a convex function (i.e., $c^{\prime}>0$ and $\left.c^{\prime \prime}>0\right)$ that accounts for the opportunity costs of resources, and the marginal cost is assumed linear (i.e., $c^{\prime \prime \prime}=0$ ).

We can express the probability expressions in (2) as

$$
\begin{aligned}
& \operatorname{Pr}\left(\sum_{i} v_{i}^{r, 1}>0\right)=\Phi\left(\frac{\bar{v}^{r, 0}+(1-\theta) \sum_{i} u\left(\tau_{i}\right)}{\sqrt{N}}\right)=\Phi^{r}, \\
& \sum_{i} \operatorname{Pr}\left(v_{i}^{\ell, 1}>0\right)=\sum_{i} \Phi\left(v_{i}^{\ell, 0}+\theta\left(2 a_{i}-1\right) u\left(\tau_{i}\right)\right)=\sum_{i} \Phi_{i}^{\ell},
\end{aligned}
$$

where, to simplify the notation, we set $\rho^{r}=\rho^{\ell}=1$ and $\sigma_{r}=\sigma_{\ell}=1$, and where $\Phi^{r}$ is the cumulative distribution function of $\sum_{i} \varepsilon_{i}^{r}$, which, by the convolution formula, is distributed as $N\left(0, \sqrt{N} \sigma_{r}\right)$, and $\Phi_{i}^{\ell}$ is the cumulative distribution function of $\varepsilon_{i}^{\ell}$. Note that $\Phi^{r}$ depends on the average margin of victory at the regional elections $\left(\bar{v}^{r, 0}\right)$, while $\Phi_{i}^{\ell}$ does not. Note also that while $\Phi^{r}$ is the same across localities, $\Phi_{i}^{\ell}$ depends on the local margin of victory $\left(v_{i}^{\ell, 0}\right)$ and on the alignment status $\left(a_{i}\right)$.

Results.-Plugging (3a) and (3b) into (2) and maximizing with respect to $\tau_{i}$, we obtain the following first-order condition:

$$
\Gamma=\left(\mu(1-\theta) \phi^{r}+\eta \theta\left(2 a_{i}-1\right) \phi_{i}^{\ell}\right) u^{\prime}\left(\tau_{i}\right)-c^{\prime}\left(\tau_{i}\right)=0, \quad \forall i
$$


where $\mu=1 / \sqrt{N}$ and $\phi=\Phi^{\prime}$ is the density function of the standard normal. This condition says that the net marginal benefit of allocating transfers should be the same across localities. ${ }^{5}$ We derive the following results.

PROPOSITION 1: Party favoritism at close local elections: provided credit spillovers exist $(\theta>0)$ and mayors' political capital is valuable $(\eta>0)$, in close local elections (i.e., when $v_{i}^{\ell, 0}=0$ ) aligned mayors will receive more transfers than unaligned mayors:

$$
\tau_{a}-\left.\tau_{u}\right|_{v_{i}^{\ell 0}=0}>0,
$$

where a stands for aligned and $u$ for unaligned.

To understand why this is the case note from (4) that $\phi_{i}^{\ell}$ is multiplied by $\eta \theta$ and $-\eta \theta$ in the aligned and unaligned cases, respectively, thus creating a wedge between the marginal benefits of transfers to these two types of municipalities (see the proof in the online Appendix). This result was previously reported in Brollo and Nannicini (2012), albeit with a slightly different specification..$^{6}$

PROPOSITION 2: Regional-level electoral competition and party favoritism: the lower the degree of regional-level electoral competition (i.e., the larger the previous margin of victory $\bar{v}^{r, 0}$ ), the higher the degree of party favoritism at close local elections:

$$
\left.\frac{\partial\left(\tau_{a}-\tau_{u}\right)}{\partial \bar{v}^{r, 0}}\right|_{v_{i}^{\ell 0}=0}>0
$$

This occurs because as $\bar{v}^{r, 0}$ decreases the regional incumbent becomes more focused on winning the regional election and less focused on winning a greater number of local elections. Because of this, transfers are spread out to all units, independently of the party to which the mayor belongs. ${ }^{7}$ This result is new in the literature and provides the main empirical prediction we aim to test.

Hypotheses.-The model predicts that, when regional elections are not too competitive, the regional incumbent will allocate more transfers to aligned than to unaligned mayors that won the local elections by a narrow margin. The model

\footnotetext{
${ }^{5}$ To guarantee a maximum, we assume that the incentives arising from local elections are not too great relative to those arising from regional elections. This ensures that the second-order condition is negative (i.e., both for aligned and unaligned municipalities).

${ }^{6}$ The model also predicts that the alignment effect vanishes as local elections become uncompetitive, that is, as $v_{i}^{\ell, 0}$ goes to 1 or -1 . So, this model predicts that the effect of alignment at close elections is greater than the effect averaged across all elections.

${ }^{7}$ As $\bar{v}^{r, 0}$ decreases, the marginal benefit curves of aligned and unaligned units become steeper, making the use of transfers more interesting. However, for a given transfer level, the difference in the marginal benefit of transfers to these two types becomes smaller, making discrimination less appealing too. See the formal proof in the online Appendix.
} 
also predicts that the lower the level of electoral competition at the regional level, the greater the difference in the amount of transfers allocated to aligned versus unaligned mayors that won the local elections by a narrow margin.

The fact that these predictions are conditional on local elections being close has implications for identification. This is what justifies the use of RD to estimating the jump in transfers at the threshold (i.e., when $v_{i}^{\ell, 0}=0$ ). RD has the advantage of providing an estimate that can be credibly interpreted as causal. Note, however, that the RD only identifies the effect of alignment at close elections (i.e., the local average treatment effect or LATE). However, the model also predicts differences in transfers between aligned and unaligned governments far from the threshold. This means that according to the model, the average treatment effect (ATE) should be lower than the LATE. In order to assess whether this is the case, we also provide "difference-in-differences" estimates for the ATE. Of course, since it is more difficult to interpret the DinD estimates as causal, we subject these results to additional reliability tests, and even then, we are cautious in our interpretation.

\section{Institutional Context}

\section{A. Local Government Finances}

The Spanish government comprises three layers: central, regional, and local. There are seventeen regional governments, the so-called Autonomous Communities (ACs), which have fairly wide-ranging spending responsibilities. Spain's local layer consists of over 8,000 municipalities, most of which are relatively small. These municipalities are multipurpose governments, with major expenditure categories corresponding to the traditional responsibilities assigned to the local public sector (e.g., environmental services, urban planning, etc.). Current spending is financed out of the municipalities' own revenues (two-thirds) and unconditional grants (one-third). The latter are allocated according to a formula, which hinders their use for pork barrel politics. However, the funding of capital spending is heavily dependent on grants, which in 2008 represented 38 percent of local investment. Capital spending represents 21 percent of total spending and, thus, capital transfers represent 8 percent $(=21$ percent $\times 0.38)$ of total nonfinancial revenues.

Capital grants to municipalities are transferred primarily from the regional layer of government ( 54 percent). There are two rationales for these grants. The first is the overlapping of responsibilities between regional and local governments. Regions use transfers to advance their policy objectives while not having to worry about the problems of implementation. The second is the ability to assist needy local governments. These transfers take the form of "project grants:" an open call is made at regular intervals and a municipality can apply by submitting its infrastructure projects (e.g., street and road paving, sewage systems and water pipes, etc.). These are evaluated according to previously established criteria (typically published in the call), but which are subject to the interpretation of the grantor. The call often does not specify clearly the weight attached to each of the criteria, or it fails to specify the link between the score assigned to each criterion and an objective variable, leaving this very much at the discretion of the grantor. 
There is anecdotal evidence that the allocation of these regional transfers has been subject to political manipulation in Spain. The following Internet posts are illustrative of partisanship in transfer allocation in two different regions:

The government of Valencia allocates all transfers on the basis of partisanship instead of adhering to objective criteria, never in accordance with the needs of the municipalities (...) year after year there is discrimination against citizens living in towns not governed by the ruling party. (https://www.vilaweb.cat/noticia/509775/20020507/bloc-sollicitasistema-equitatiu-partidista-repartiments-dajudes-diputacio-ajuntaments. html 05/07/2002)

The other problem [with transfers] is the 'old-boy network' and the 'partisanship' of grantors. (...) Having a 'friend in the right place' and being a 'member of the party' weigh much more heavily than they should in the awarding of transfers. (https://blocs.mesvilaweb.cat/sbaulida/?p=84854 03/10/2008)

There is also some evidence that the different agents involved do care about who receives the credit for the facilities built with these transfers. For instance, in 2009, when the Spanish socialist government, as part of a stimulus package, decided to allocate capital transfers on a per capita basis, many socialists in opposition at the local level complained about how this would harm their electoral prospects at the next municipal elections. Similarly, the central government sought to get the political credit for these stimulus transfers by ordering the installation of huge billboards on the public work sites stating clearly that the central government was responsible for the program. All this evidence supports the credit-claiming mechanism, which explains why the regional incumbent is interested in discriminating in favor of aligned mayors.

\section{B. Regional and Local Politics in Spain}

Regional Politics. - Elections to the regional parliament are held every four years. Voters choose between several party lists, and the electoral system is based on the d'Hondt rule with a threshold. Representatives elect the regional president by simple majority and she, in turn, decides the composition of the Cabinet. Around a third of the incumbents sit in minority or coalition governments. Coalitions tend to form along ideological lines, albeit with a few exceptions. There are three national parties that run in all regions: PSOE (the main party on the left), PP (the only national party on the right), and IU (the former communists). There are also many regionally based parties, some on the left and some on the right. Some of these parties seldom cross ideological bloc lines. Other parties are able to reach agreements with both the left and the right. In any case, the vast majority of regional presidents belong to the PSOE and the PP (36 and 51 percent, respectively, in our sample). Regionalist parties held the regional presidency in the rest of the cases (13 percent). We take these characteristics into account in our analysis (see Tables A.7 and A.8 in the online Appendix).

Most regional elections and local elections are concurrent (i.e., held on exactly the same day). This happens in 12 out of the 15 regions in our sample, meaning that 
only in 3 regions regional and local elections are staggered (in Galicia, Catalonia, and Andalusia). In this latter group, the lapse between local and regional elections is between one and two years, suggesting that even in this case the regional incumbent might care about the competitiveness of future regional elections. In any case, we use all regional elections in order to obtain our main results. We also examine whether these are robust to the exclusion of the regions with staggered elections.

Local Politics.-Local elections are held every four years on the same day throughout all the Spanish municipalities. Voters choose between several closed party lists. The electoral system is a proportional one, votes being allocated to seats using the d'Hondt rule with a 5 percent vote threshold. After that the mayor is elected by a simple majority of the council (see Colomer 1995). The council operates as a small representative democracy, and has to reach a majority vote to pass the initiatives and regulations proposed by the mayor, who acts as the agenda-setter. Mouritzen and Svara (2002) classify Spanish mayors as "strong mayors," meaning "the elected mayor is in control of the majority of the city council and in full charge of all executive functions." Moreover, the discipline enforced by Spain's political parties means that the chances of amending the mayor's proposals are low when the mayor's party or coalition controls a majority of the seats.

The fairly large proportion of minority or coalition governments is undeniable (around one-third during the terms analyzed here), although most of these coalitions are formed along ideological lines. There are, of course, some exceptions to this rule. For instance, when a regionalist party crosses the ideological border and supports a regional president of a different ideology, this generates some pressure on their local co-partisans to do the same and to support the candidate for mayor belonging to the president's party. Moreover, the platforms of the few local parties tend to be based solely on local issues, so they are under less pressure to reach an agreement on ideological grounds or because of pressure from higher party ranks. We show that the results are robust to different ways of dealing with these parties. Note, in any case, that these two problems are of no quantitative relevance. As in the case of regional governments, most mayors belong to the PSOE or the PP (48.5 and 37.5 percent, respectively, in our sample). Regionalist parties only held 10.6 percent of mayoralties and this figure is much lower for regionalist parties crossing ideological lines (1.6 percent). The percentage of local parties holding the mayoralty is also low (3.4 percent).

\section{Empirical Design}

\section{A. RD and PR Systems}

Studies adopting observational approaches to estimate the effect of party ideology on votes and policy outcomes may suffer from an omitted variables problem: party control can be correlated with an incumbent's popularity and this, in turn, might impact the outcome variable. To deal with this problem some papers have recently adopted the "close-race" regression discontinuity design (RD) framework 
(see Lee 2008; Lee, Moretti, and Butler 2004; Pettersson-Lidbom 2008; Ferreira and Gyourko 2009; Gerber and Hopkins 2011; Folke 2014; Meyersson 2014). The reasoning underpinning this method is that elections won by a narrow margin are, in practice, very similar events to elections lost by a similarly narrow margin.

The fact that local councils are elected in Spain using party-list proportional representation (PR) precludes the use of a traditional $\mathrm{RD}$. The first challenge posed by such institutional setting is that sometimes no single party holds a majority of seats in the council, which means that the mayor has to be supported by a coalition of parties. The second challenge concerns the difficulties in identifying the vote threshold at which an additional vote switches a seat from one party to another (and, thus, from the coalition supporting the mayor to the opposition). Here, we follow the solution proposed by recent studies that have adapted the RD methodology to a PR system (see Folke 2014 among others).

First, provided that ideology is a very powerful driver of coalition formation, we define our treatment as a situation in which the ideological bloc of the party of the regional president has a majority of seats at the local council. So, when parties on the left of the ideological spectrum have a majority of seats, it is highly likely that the mayor will also belong to the left-wing party bloc. If the regional president belongs to a left-wing (right-wing) party, then we can say that the mayor and the president are aligned (unaligned). The same applies when right-wing parties hold a majority of seats. This is exactly the procedure used in Fiva, Folke, and Sørensen (2018), and Fiva and Halse (2016). However, the fact that a small proportion of regional and local parties are able to support both right- and left-wing parties means that the ideological factor will not always work. In the case of regional parties, we classify them as belonging to the ideological bloc of the president, if they support that party in the regional parliament. The evidence that regional coalitions tend to reproduce at the local level justifies this procedure. In any case, we use a "fuzzy" RDD, as in Fiva and Halse (2016), to take into account the fact that ideology does not predict with certainty the alignment status.

Second, even if the treatment in terms of the discontinuity of seats is relatively straightforward to define, elections won or lost by a difference of one seat are probably not that close in terms of the number of votes. Thus, using the number or the percentage of seats as our forcing variable might not be appropriate (see Fiva, Folke, and Sørensen 2018 for a discussion of this point). Instead, we use a forcing variable computed as the percentage of votes that the ideological bloc of the regional president must lose (win) in order to lose (win) the majority of seats in the council. We explain in detail how this procedure works in the following section and in the online Appendix (see Tables A.3, A.4, A.5, and A.6).

\section{B. Equation Specification}

Average Effects.-The $\mathrm{RD}$ analysis involves, as a first step, the estimation of the discontinuity of transfers. To do so, we use the following two-equation model:

$$
\tau_{i t}=\alpha a_{i t}+g\left(v_{i t}^{0}\right)+\varepsilon_{i t}
$$




$$
a_{i t}=\beta d_{i t}+h\left(v_{i t}^{0}\right)+\epsilon_{i t}, \quad \forall v_{i t}^{0} \in(-h, h),
$$

where $\tau_{i t}$ are the per capita capital transfers received by the local government $i$ before local election $t$ and $a_{i t}=1$ if there is alignment between the regional and the local government, and 0 otherwise. The variable $v_{i t}^{0}$ is the percentage of votes in the previous local elections that the parties in the regional president's ideological bloc would have to lose (if holding the mayoralty) or win (if in the opposition at the local level) to lose (win) a majority of seats in the local council, and so lose (win) control of the government. This variable is computed using a specific algebraic method developed herein. Henceforth, we refer to this variable as the Regional incumbent's bloc vote margin. With $d_{i t}=1$ we denote a situation where this vote margin is positive, and 0 otherwise. The terms $g\left(v_{i t}^{0}\right)$ and $h\left(v_{i t}^{0}\right)$ are polynomials in $v_{i t}^{0}$, fitted separately at either side of the threshold using the observations in a neighborhood around the threshold, which we label by $h$, hereby referred to as the bandwidth.

Equation (7) is used to estimate the effect of partisan alignment on transfers. Equation (8) is the first stage used to estimate the discontinuity in alignment that we use for identification. We estimate equation (7) by 2SLS, using $d_{i t}$ as an instrument for $a_{i t}$. The estimates obtained can be interpreted as a "Local Average Treatment Effect" or LATE (see Lee and Lemieux 2010).

As explained above, we also report the DinD results, given that they may provide information about average treatment effects and can, in any case, be used as a background check. The DinD equation can be expressed as follows:

$$
\tau_{i t}=\gamma_{1} a_{i t}+\sum_{i} \gamma_{2 i} f_{i}+\sum_{t} \gamma_{3 t} f_{t}+u_{i t}
$$

where $f_{i}$ and $f_{t}$ are municipality and term-of-office dummies.

Heterogeneous Effects.-The specification in (7) can be modified to analyze the heterogeneous effects of interest. In particular, following Becker, Egger, and von Ehrlich (2013), we estimate an "Heterogeneous Local Average Treatment Effect" (HLATE) interacting our treatment with an indicator of regional electoral competition. More concretely, we estimate the following equation:

$$
\tau_{i t}=\eta_{1} a_{i t} z_{r t}+\eta_{2} z_{r t}+\sum_{r} \eta_{3 r} a_{i t} f_{r}+\sum_{r} \eta_{4 r} f_{r}+l^{r}\left(v_{i t}^{0}\right)+l\left(v_{i t}^{0}, z_{r t}\right)+v_{i t},
$$

where $z_{r t}$ is the level of regional electoral competition (demeaned) and $\eta_{1}$ is the parameter of interest, which indicates how the alignment effect changes as the degree of electoral competition deviates from the mean. The terms $a_{i t} f_{r}$ and $f_{r}$ denote alignment $\times$ region fixed effects and region dummies, respectively. The expression $l^{r}\left(v_{i t}^{0}\right)$ denotes a region-specific polynomial and $l\left(v_{i t}^{0}, z_{r t}\right)$ is an interaction between the polynomial and $z_{r t}$. All the polynomials are fitted separately on each side of the threshold (see Table A.9 in the online Appendix for details). The inclusion of alignment $\times$ region fixed effects in the equation means that the estimation of our heterogeneous effects only relies on variation over time in the level of regional 
competition. ${ }^{8}$ Intuitively, we estimate how the alignment effect strengthens (loosens) as the level of regional electoral competition decreases (increases) over time.

\section{Econometrics}

$R D$ Assumptions.-The validity of the RD design rests on certain assumptions that have to be tested. First, we document that there is a genuine discontinuity in the probability of treatment. We show graphically that this is the case. The jump in the probability of treatment is lower than one, and this justifies the use of a "fuzzy" design. Second, we show that the forcing variable used is continuous around the threshold by inspecting the histogram and using the formal test proposed by McCrary (2008). The continuity test provides a means for discarding the manipulation of the forcing variable. Third, we also test for the continuity of predetermined covariates to show that all factors, besides alignment, that could potentially influence the level of transfers are continuous at the threshold.

In order for the RD estimates of the heterogeneous effects to be valid, two additional assumptions need to be fulfilled (see Becker, Egger, and von Ehrlich 2013). The first is that the source of heterogeneity $\left(z_{r t}\right)$ also has to be continuous at the threshold. We provide evidence on this. The second assumption is that, conditional on the forcing variable, the assignment of the interaction variable has to be random, which means that conditional on the polynomial of the vote margin at the local elections, municipalities in regions with high- and low-regional electoral competition should not differ in unobserved factors that may influence the allocation of transfers. As we explained above, our main strategy to ensure that the results are not driven by the omission of confounding factors of this type is based in using Alignment $\times$ Region fixed effects. Additionally, we add interactions between alignment and time-varying confounders that one might reasonably think have an influence on the allocation of transfers and that might be correlated with the evolution of regional electoral competition over time.

To validate the DinD results, we perform a falsification test that shows that the results are driven by partisan alignment and not by any other confounder that correlates over time with alignment. ${ }^{9}$ To perform this test, we study whether future partisan alignment has an impact on transfers received in the present, controlling for present alignment.

Estimation and Inference.-First, our preferred RD estimation uses a local polynomial with $h$ equal to the optimal bandwidth, $h^{*}$, computed as per Calonico, Cattaneo, and Titiunik (2014). This bandwidth minimizes the mean squared error. We also report the results for other bandwidths: $h^{*} / 2, h^{*} / 4$, and $2 h^{*}$. The finding that the treatment is also precisely estimated for lower bandwidths would reassure our findings. The results reported in the tables are based on the estimation of a

\footnotetext{
${ }^{8}$ The estimation will deliver the coefficients of each of the Alignment $\times$ Region fixed effects (i.e., $\eta_{3 R}$ ). Note that the variation in these coefficients does not have a causal interpretation, since they can be correlated with omitted variables measured at the regional level.

${ }^{9}$ Ideally, we would like to test the parallel trend assumption. However, our data does not allow performing this test. We only have three cross sections.
} 
local linear regression that facilitates later on the specification and estimation of the interacted model. As a complementary analysis, we also report the results of an RD analysis using a global polynomial. Second, regarding the calculation of the standard errors, when we estimate the HLATE, we cluster them at the regional level to account for the fact that the interacted variable is also computed at the regional level. We account for the fact that we have a relatively small number of clusters by reporting wild-bootstrap $p$-values (Cameron and Miller 2015).

\section{Sample and Data}

Sample.-We use data for Spanish municipalities and regions (i.e., Autonomous Communities, ACs). We consider three cross sections of data, for the terms 1996-1999, 2000-2003, and 2004-2007, with around 2,000 municipalities in each period. The outcomes of the 1995 election affect transfers in 1996-1999; the 1999 election influences the 2000-2003 transfers; and the 2003 election has an impact on the transfers allocated during 2004-2007. The information comes from a survey on budget outlays conducted by the Spanish Ministry of Finance. This database includes all municipalities larger than 5,000 residents and a representative sample of the rest. ${ }^{10}$

Transfers.-We focus on capital transfers from regional to local governments in the two years preceding the next local election. As explained in Section II, we study capital grants because of the greater discretion in their allocation. We expect them to matter more in the period running up to local elections. Further, the two-year aggregation helps to reduce the volatility of the variable, and the use of yearly information does not provide any statistical advantage, since the alignment status does not change between years within these two-year periods.

Alignment.-The alignment concept used throughout this study can be defined as a dummy equal to one when the mayor and the regional president belong to the same party (Mayor-President alignment). We consider that it is in such cases that the incentive to avoid losing credit for the transfers allocated is strongest. In the robustness checks, we have also sought to verify whether the results are affected by the use of more comprehensive alignment definitions: that is, situations in which the mayor and/or the main partner of a coalition belong to the same party (Partner alignment), and situations in which the mayor and the regional president belong to the same ideological bloc (Bloc alignment).11

\footnotetext{
${ }^{10}$ Due to data accessibility problems, the analysis is restricted to 15 regions, excluding the Basque Country and Navarra. These are small regions and their exclusion should not represent a problem. Moreover, data availability also restricts the sample to municipalities with more than 1,000 residents.

${ }^{11}$ Note that when examining the effect of Mayor-President Alignment, municipalities with other types of alignment are excluded from the sample. Thus, the control group is formed by local governments ruled by a party from the regional opposition (either in majority or in coalition). A similar logic applies when examining other types of alignment.
} 
Forcing Variable.-The forcing variable is the Regional incumbent's bloc vote margin, computed as the votes needed for the ideological bloc of the regional incumbent to win (lose) the majority of seats on the local council, expressed as a percentage of total votes cast at the local elections. To define the ideological blocs, we classify all parties standing at local elections in three groups: left, right, and local parties (see Table A.3 and Table A.8 in the online Appendix for further details on the classification). Some local parties are difficult to classify. We consider this issue in the robustness checks.

We develop an exact algebraic formulation of the forcing variable based on the workings of the d'Hondt method, which is used to translate votes into seats in Spanish local elections. ${ }^{12}$ We compute the forcing variable under different vote migration scenarios. In our preferred measure (used to present our main results), we assume that the votes taken away from the party holding the marginal seat are transferred only to abstention and not to the parties in the other ideological bloc. ${ }^{13} \mathrm{We}$ also assume that negative vote shocks simultaneously affect all the parties within the regional incumbent's ideological bloc, so we subtract votes not just from the party holding the marginal seat but from all parties in the bloc in proportion to the initial votes received by each party. Intuitively, our method works as if we were subtracting small numbers of votes from one of the blocs, distributing these votes between the parties of that bloc according to their initial vote share, while keeping the number of votes for the parties of the other bloc constant. We stop subtracting votes when we observe a shift in the seat majority from one bloc to the other (i.e., when the last seat giving the majority to one bloc moves to the other bloc). The number of votes needed to reach this stage, divided by the total number of votes, is our forcing variable. ${ }^{14}$

As a robustness check, we also compute the forcing variable using an alternative vote migration scenario. We consider that a vote might go (come) not just from (to) abstention but also from (to) the other ideological bloc, as well as a combination of these two assumptions. ${ }^{15}$

Regional-Level Electoral Competition.-Our measures of regional electoral competition are based on the difference between the seat shares controlled by the regional president and those controlled by the opposition (henceforth, Regional seat margin). We use seats instead of votes because regional elections have multiple districts and different degrees of proportionality in different regions, which renders vote shares meaningless (see e.g., Strom 1989). Note also that the purpose here is different to that when we compute the forcing variable with local election data: in

\footnotetext{
${ }^{12}$ See Table A.4 in the online Appendix for an example of how it is implemented.

${ }^{13} \mathrm{We}$ believe this assumption to be plausible in Spain given the importance of vote transfers from/to abstention during the period of analysis.

${ }^{14}$ In Table A.3 in the online Appendix, we provide the algebraic formulation for the more basic case, i.e., the one in which the bloc holding a seat majority has only one seat in excess and it is clear that the next seat to be allocated belongs to the opposition bloc. In Table A.5, we provide a numerical example to illustrate how this might work in a more complicated scenario (i.e., the seat share difference between government and opposition is larger than one).

${ }^{15}$ In Table A.6 in the online Appendix, we provide a numerical example.
} 
that case we sought to make treated and control groups comparable, whereas here we seek to capture differences across regions.

The three measures we use differ in their degree of inclusiveness of the parties supporting and opposing the regional president. In the first measure, we compute the Regional seat margin as the difference between the seat share of the parties that actually support the regional president in the parliament (i.e., those voting YES in the investiture) and the seat share of the parties that do not support the president. Here, we include the main parties in the opposition bloc, that is, those parties that belong to a different ideological bloc (and voted NO in the investiture). This is our preferred measure since it is a much more accurate depiction of the threats the different regional governments actually face. In the second measure, we expand the definition and include the seats of all the parties included in the two ideological blocs; in this case, however, we exclude some parties that are unwilling to vote for an ideologically close party for specific reasons (i.e., radical preferences, conflictive scissions). The difference between this and the first measure is that, in some cases, it expands the seat share of the regional president, since it allows the president to count on ideologically close parties that do not actually belong to the ruling coalition (because the party is a single-party government or because the president chose a centrist regionalist party as a partner). The disadvantage of this second measure is that it relies on hypothetical rather than on real alliances. The third measure compares the seat shares of the main parties in government and in opposition. Research on local government coalition formation in countries with a PR system shows that a party's seat share is the variable that best predicts whether this party is going to win control of the government (e.g., Skjæveland and Serritzlew 2010). A shortcoming of this variable is that it neglects the fact that, on some occasions, there are parties in the opposition bloc that are ideologically close and prone to reaching an agreement even without a pre-electoral coalition.

Our preferred measure is the first one. Thus, we present the detailed results for this variable while the others are presented as additional analysis in the online Appendix. It is important to note that this variable (as the other two) has enough time variation (which is the one used to identify the HLATE in equation (10)). This can be seen in Figure 1 that reports a box-plot both for the "within" and the "between" variation in the Regional seat margin. The fact that the "within' variable is less concentrated around the median might help in our case since the interaction variable is a continuous one. ${ }^{16}$

Control Variables.-In order to provide a further check of the reliability of the RD results and to improve the efficiency of our estimates, we also present results when controlling for several covariates. The variables included are those already used in previous studies (Solé-Ollé and Sorribas-Navarro 2008): $\log$ (Population), Population density, Property tax rate, Assessed property value, and Local debt level. See Table A.1 in the online Appendix for the sources of all variables.

\footnotetext{
${ }^{16}$ The box-plot graph also identifies more potential outliers in the "between" than in the "within" case. In the first case there are two elections (in Cantabria) outside the plots' range while in the "within" case there are five (three in Canarias and two in Cantabria).
} 


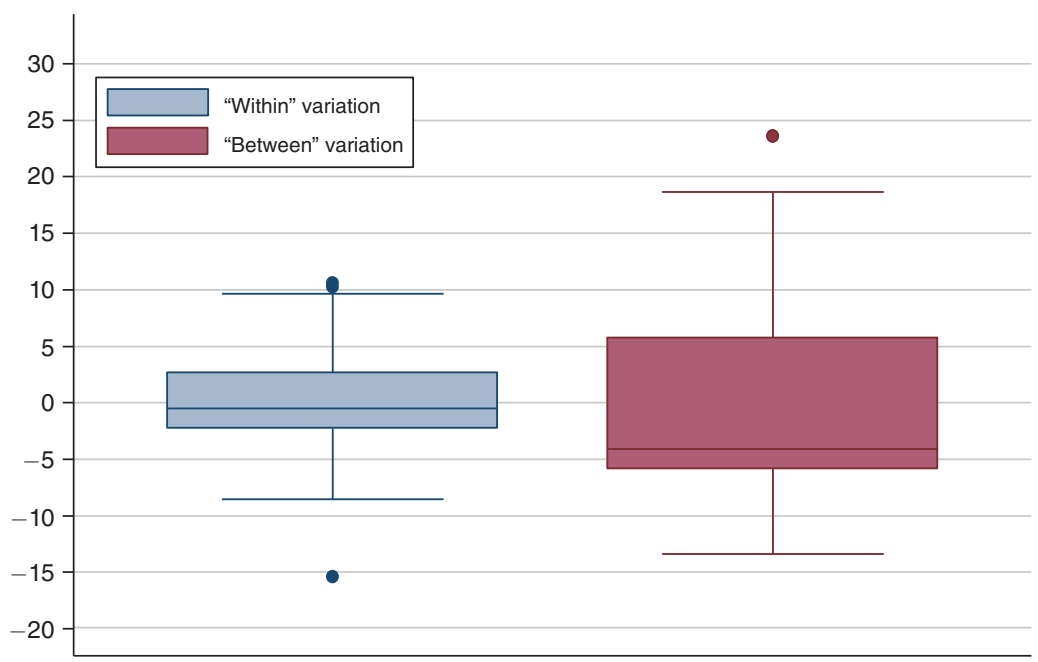

Figure 1. Variation in Regional Seat Margin

Panel A. Seat margin

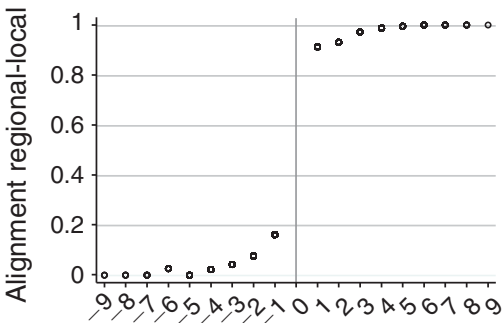

Regional incumbent's bloc seat margin
Panel B. Vote margin

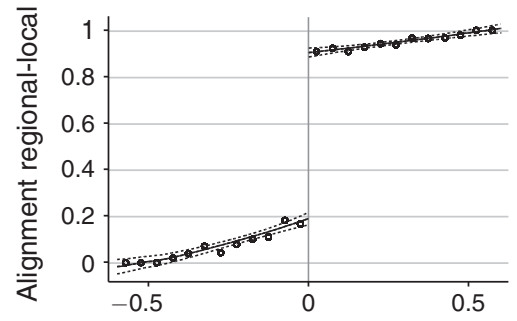

Regional incumbent's bloc vote margin

Figure 2. Alignment versus Forcing Variable

Notes: 1995-1999, 2000-2003, and 2004-2007 terms. Alignment Regional-Local $=1$ if the mayor and the regional president belong to the same party. Regional incumbent's bloc seat margin $=$ distance in local council seats to a change in the ideological bloc's seat majority. Regional incumbent's bloc vote margin = distance in percentage of local election votes to a change in the ideological bloc's seat majority; seats and votes as obtained at the 1995, 1999, and 2003 local elections. The dots are bin averages of 5 percent bin size. The solid line represents the predicted values of a local linear polynomial smoothing on each side of the threshold. The dashed lines are 95 percent confidence intervals. See Table A.1 in the online Appendix for definitions and sources.

\section{Results}

\section{A. Exploring the Discontinuity}

Panel A in Figure 2 plots the seat margin of the regional incumbent's bloc at the local elections against its alignment status. The graph shows a considerable jump when the ideological bloc of the regional incumbent moves from -1 to +1 seat (i.e., one additional seat needed to gain/lose a majority of seats). 
Panel A. Histogram

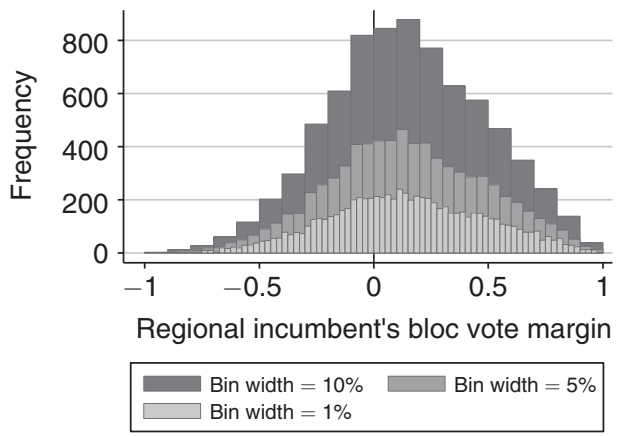

Panel B. McCrary test

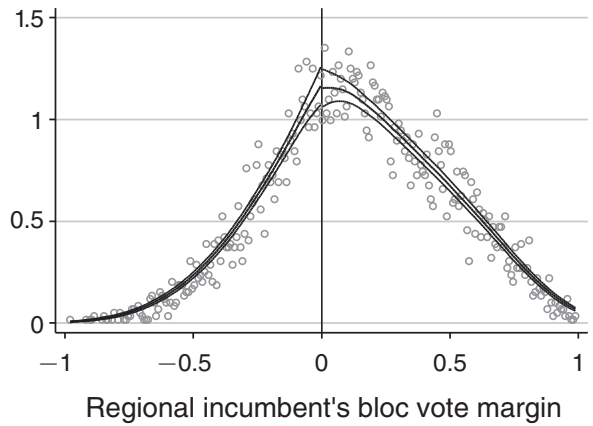

Figure 3. Continuity of the Forcing Variable

Notes: Dots for the McCrary graph: bin averages of the density of forcing variable (Regional incumbent's bloc vote margin). Computed with McCrary's (2008) Stata program.

The group of municipalities located at the -1 and +1 seat margin values is quite large and has considerable internal variability in the popularity of the party of the regional incumbent. For this reason, we use the vote margin as the forcing variable, computed as the percentage of votes needed for the regional incumbent's bloc to win (lose) a majority of seats on the city council. Panel B in Figure 2 shows the plot between this forcing variable and the alignment status. From this figure, we see that there is a big jump in the probability of alignment when moving from positive to negative values near the threshold. The value of the discontinuity in the first stage (i.e., the discontinuity in the probability of alignment) is around 70 percent. The results do not depend at all on the bandwidth or on the method of estimation (local versus global polynomial).

To test that the forcing variable is not manipulated, we examine its histogram and, more formally, we test for the continuity of this variable at the cut-off. Figure 3 shows no evidence of manipulation. Another validity check involves testing for the presence of a discontinuity in the predetermined covariates used as controls and further observables that are potential confounders. None of the variables is systematically discontinuous at the threshold (see Table A.10 and Figure A.1 in the online Appendix).

\section{B. Partisan Alignment and Transfers}

The discontinuity in transfers around the cut-off is illustrated in Figure 4, which shows the plot between capital transfers and the forcing variable. The graph provides evidence of a clear and sizeable discontinuity around the threshold: municipalities marginally to the right of the cut-off (those likely to be aligned) receive larger transfers than those marginally to the left (those likely to be unaligned).

Panel A of Table 1 presents the RD estimates of the LATE, which corresponds to the second stage of a 2 SLS regression, where the dependent variable is capital transfers per capita. The optimal bandwidth $h^{*}$ is equal to 19.3 percent, which is similar 


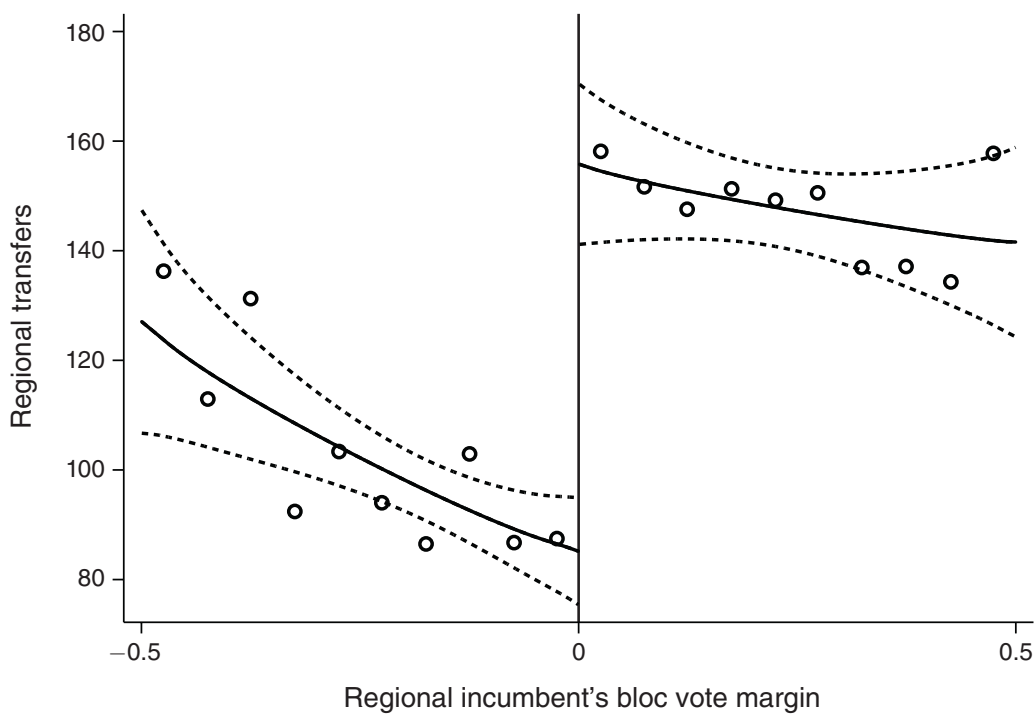

Figure 4. Capital Transfers versus Regional Incumbent’s Vote Margin

Notes: (i) Regional transfers = capital transfers per capita from the regional to the local government during the last two years of the 1995-1999, 2000-2003, and 2004-2007 municipal terms. (ii) The dots are bin averages of 5 percent bin size. (iii) The solid line represents the predicted values of a local linear polynomial smoothing on each side of the threshold. (iv) The dashed lines are 95 percent confidence intervals.

Table 1-Average Effect of Partisan Alignment on Capital Transfers

\begin{tabular}{|c|c|c|c|c|c|c|}
\hline & \multicolumn{5}{|c|}{$\mathrm{RD}$} & \multirow{2}{*}{$\begin{array}{c}\text { DinD } \\
(6)\end{array}$} \\
\hline & $\begin{array}{l}\text { Global } \\
\text { (1) }\end{array}$ & $\begin{array}{l}\text { Local } \\
(2)\end{array}$ & $\begin{array}{l}\text { Local } \\
(3)\end{array}$ & $\begin{array}{l}\text { Local } \\
(4)\end{array}$ & $\begin{array}{l}\text { Local } \\
(5)\end{array}$ & \\
\hline \multicolumn{7}{|c|}{ Panel A. Second stage (dependent variable: capital transfers per capita) } \\
\hline Alignment & $\begin{array}{c}98.06 \\
(15.71) \\
{[0.000]}\end{array}$ & $\begin{array}{c}94.79 \\
(13.72) \\
{[0.000]}\end{array}$ & $\begin{array}{l}102.57 \\
(18.65) \\
{[0.001]}\end{array}$ & $\begin{array}{c}86.99 \\
(23.40) \\
{[0.000]}\end{array}$ & $\begin{array}{c}71.70 \\
(31.40) \\
{[0.049]}\end{array}$ & $\begin{array}{l}56.14 \\
(6.33) \\
{[0.000]}\end{array}$ \\
\hline \multicolumn{7}{|c|}{ Panel B. First stage (dependent variable: alignment status) } \\
\hline $\begin{array}{l}\text { Regional incumbent's } \\
\text { bloc seat majority }\end{array}$ & $\begin{array}{l}0.70 \\
(0.02) \\
{[0.000]}\end{array}$ & $\begin{array}{l}0.71 \\
(0.02) \\
{[0.000]}\end{array}$ & $\begin{array}{l}0.71 \\
(0.03) \\
{[0.000]}\end{array}$ & $\begin{array}{l}0.73 \\
(0.04) \\
{[0.000]}\end{array}$ & $\begin{array}{l}0.72 \\
(0.05) \\
{[0.000]}\end{array}$ & - \\
\hline$R^{2}$ & 0.749 & 0.684 & 0.610 & 0.567 & 0.570 & - \\
\hline Polynomial order & 2 & 1 & 1 & 1 & 1 & - \\
\hline Bandwidth (percent) & 100 & $2 h^{*}=38.6$ & $h^{*}=19.3$ & $h^{*} / 2=9.65$ & $h^{*} / 4=4.8$ & \\
\hline Observations & 6,050 & 4,410 & 2,576 & 1,383 & 683 & 6,050 \\
\hline
\end{tabular}

Notes: 1995-1999, 2000-2003, and 2004-2007 terms. Columns 1-4 in panel A show the second-stage estimates of the 2SLS where Regional incumbent's bloc seat majority (dummy equal to 1 if the regional incumbent's bloc vote margin $>0$ ) is used as an instrument for the Alignment dummy (equals 1 if the mayor and the regional president belong to the same party); column 6 shows the difference-in-differences estimates. Panel B shows the first-stage estimates of a 2SLS regression where the dependent variable is Alignment. Robust standard errors are in parentheses, clustered at the municipality level. The figures in brackets show the $p$-values obtained if we cluster standard errors at the regional level and implement wild bootstrapping. RD estimates in columns $2-5$ are obtained using local linear regressions using different bandwidths 5; the optimal bandwidth is based on the procedure proposed by Calonico, Cattaneo, and Titiunik (2014). 
to other close-election studies (see, e.g., Meyersson 2014). The 2SLS coefficient associated with the optimal bandwidth is around 102 euros and it is very precisely estimated. This amount has to be compared with the transfers received by unaligned municipalities just at the left of the cut-off, which are around 100 euros per capita. Thus, an aligned municipality would receive, on average, approximately twice per capita transfers than a similar unaligned one. The coefficients that we get when using smaller bandwidths are a little smaller but also quite sizable and still precisely estimated. The local RD results are also robust to the use of nonparametric methods and to the inclusion of control variables (see Figure A.2 and Table A.11 in the online Appendix). 17

Overall, the results are statistically significant, robust, and quantitatively meaningful. The degree of party favoritism in the allocation of these transfers therefore seems very high. However, the impact on local public finances is not so great once the share of the transfers in local budgets has been accounted for. Transfers from regional governments represent 54 percent of the capital transfers received by municipalities, which in turn represent 20.52 percent of local capital spending. Therefore, a 102 percent increase in such transfers would help municipalities increase their capital spending by 20.93 percent $(=102$ percent $\times 20.52$ percent $)$.

The last column in Table 1 also reports the DinD coefficient. The effect estimated is 51.70 euros and, therefore, much smaller than that obtained when using RD. There are two possible explanations for this difference. First, it is less clear that the DinD estimates are causal. They could be biased downward. For instance, this would happen if local governments switch from being unaligned to aligned after the previous local election, and that higher transfers were the cause of this. Second, the DinD might be an estimate of the ATE-recall that our model suggests that the ATE should be smaller than the LATE.

Column 1 in Table A.13 reports the falsification test performed to validate the DinD results. The estimate shows that future alignment does not affect the allocation of transfers, while the effect of present alignment remains unchanged. This result suggests that it is unlikely that the DinD estimates are downward biased and that the more plausible explanation is that the DinD are an estimate of the ATE.

Additionally, in column 2 of Table A.13, we estimate the effect of past alignment, conditional on present alignment. The contemporaneous effect of alignment remains statistically significant and past alignment has no statistically significant effect. This result validates our story. Finding otherwise would mean that alignment only has an effect after the election, which does not make much sense if incumbents use transfers to buy votes.

\section{The Role of Regional Level Electoral Competition}

Before presenting the HLATE estimates from equation (10), a clear way to show that regional electoral competition can curb party favoritism is to present a graphical

\footnotetext{
${ }^{17}$ Note also that the global polynomial results are very similar in size. The polynomial of order two is the one that maximizes the goodness-of-fit, but the results are robust to the order of the polynomial chosen (see Table A.12 in the online Appendix).
} 
Panel A. Low competition

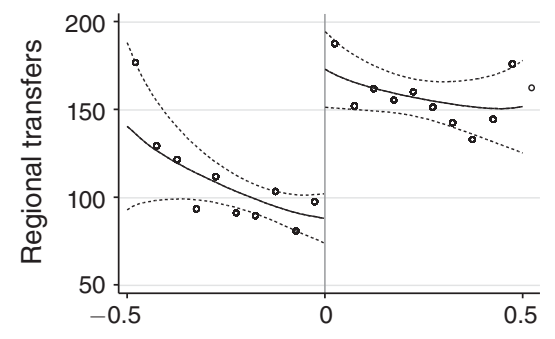

Regional incumbent's bloc vote margin
Panel B. High competition

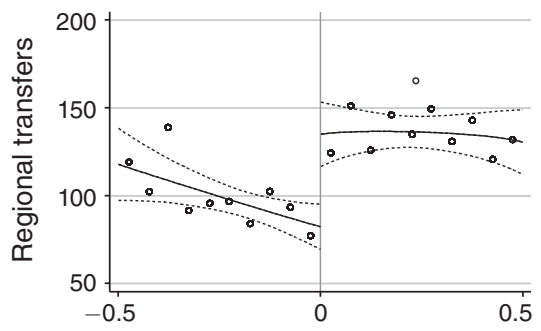

Regional incumbent's bloc vote margin

Figure 5. Low versus High Competition Regions

Notes: The solid line represents the predicted values of a local linear polynomial smoothing on each side of the threshold. Regions are divided into "low" ("high") competition if the Regional seat margin is above (below) the median. The dashed lines are 95 percent confidence intervals.

analysis of the LATE for two subsamples. One includes observations where regional electoral competition is above the median (low competition), and the other includes observations with regional electoral competition below the median (high competition). As it can be seen in Figure 5, the difference between the amounts of capital transfers allocated to aligned and unaligned municipalities is substantially larger in regions where regional political competition is low than in regions where it is high. In a region with low (high) political competition, an aligned municipality would receive $116.63 €(63.56 €)$ per capita more than an unaligned municipality. These amounts have to be compared with the transfers received by unaligned municipalities just at the left of the cut-off, which are $83 €(90 €)$ per capita. Thus, an aligned municipality in a region where political competition is low would receive 140 percent more per capita transfers than a similar unaligned one. If regional competition were high, an aligned municipality would receive 70 percent more per capita transfers than a similar unaligned one.

However, as instructive as this analysis might be, it has some limitations. First, being a region with a high or a low level of regional electoral competition might be correlated with many other regional traits. Second, the efficiency of the estimator might be substantially improved by exploiting the whole range of variation in the regional competition variable instead of using only a dummy. So, our estimation of the HLATE is based on a specification that interacts the alignment with the Regional seat margin and that exploits the variation over time in the degree of regional competition in order to wash out the effects of fixed regional traits. Before showing the results, we present evidence that the interacting variable (i.e., the Regional seat margin) is continuous at the threshold, which is one of the assumptions required for the identification of the HLATE. In Figure 6, we show that this is indeed the case. The variable is clearly continuous at threshold, as also a more formal test certifies (see Table A.10 in the online Appendix).

In Table 2, we present empirical evidence that, when regional incumbents face uncontested regional elections, the level of party favoritism in the allocation of 


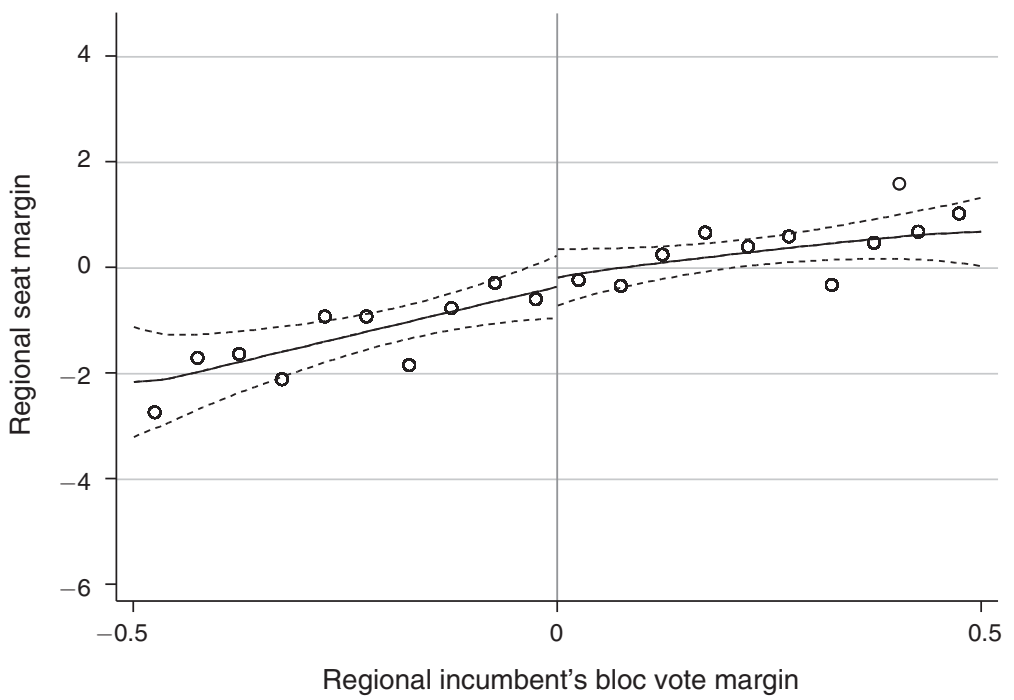

Figure 6. Continuity of the Regional Seat Margin

Notes: The dots are bin averages of 5 percent bin size. The solid line represents the predicted values of a local linear polynomial smoothing on each side of the threshold. The dashed lines are 95 percent confidence intervals. The $y$-axis plots the variable Regional seat margin, which is the difference between the seat shares of the parties in the regional government and those of the parties in the opposition in the last regional election (demeaned).

Table 2-Effect of Regional Electoral Competition on Party Favoritism

\begin{tabular}{|c|c|c|c|c|c|c|}
\hline & \multicolumn{5}{|c|}{$\mathrm{RD}$} & \multirow{2}{*}{$\begin{array}{c}\operatorname{DinD} \\
(6)\end{array}$} \\
\hline & $\begin{array}{l}\text { Global } \\
(1)\end{array}$ & $\begin{array}{l}\text { Local } \\
(2)\end{array}$ & $\begin{array}{l}\text { Local } \\
(3)\end{array}$ & $\begin{array}{c}\text { Local } \\
(4)\end{array}$ & $\begin{array}{l}\text { Local } \\
(5)\end{array}$ & \\
\hline $\begin{array}{l}\text { Alignment } \times \\
\quad \text { Regional seat margin }\end{array}$ & $\begin{array}{l}8.55 \\
(2.60) \\
{[0.000]}\end{array}$ & $\begin{array}{l}7.24 \\
(3.28) \\
{[0.051]}\end{array}$ & $\begin{array}{l}7.71 \\
(3.62) \\
{[0.046]}\end{array}$ & $\begin{array}{l}12.57 \\
(4.53) \\
{[0.000]}\end{array}$ & $\begin{array}{l}8.04 \\
(4.40) \\
{[0.064]}\end{array}$ & $\begin{array}{l}3.58 \\
(1.61) \\
{[0.018]}\end{array}$ \\
\hline Regional seat margin & $\begin{array}{l}-0.94 \\
(2.10) \\
{[0.693]}\end{array}$ & $\begin{array}{l}1.56 \\
(1.41) \\
{[0.374]}\end{array}$ & $\begin{array}{l}1.22 \\
(1.26) \\
{[0.381]}\end{array}$ & $\begin{array}{l}0.72 \\
(3.27) \\
{[0.842]}\end{array}$ & $\begin{array}{l}2.69 \\
(6.66) \\
{[0.518]}\end{array}$ & $\begin{array}{l}-0.50 \\
(1.42) \\
{[0.740]}\end{array}$ \\
\hline $\begin{array}{l}\text { Polynomial order } \\
\text { Bandwidth (percent) } \\
\text { Observations }\end{array}$ & $\begin{array}{r}2 \\
100 \\
6,050\end{array}$ & $\begin{array}{c}1 \\
2 h^{*}=38.6 \\
4,410\end{array}$ & $\begin{array}{c}1 \\
h^{*}=19.3 \\
2,576\end{array}$ & $\begin{array}{c}1 \\
h^{*} / 2=9.65 \\
1,342\end{array}$ & $\begin{array}{c}1 \\
h^{*} / 4=4.8 \\
644\end{array}$ & 6,050 \\
\hline
\end{tabular}

Notes: In columns 1-5, Alignment is instrumented with seat majority (see Table 1); columns 1-5 include interactions between Alignment and the Regional seat margin variable, and a polynomial of the forcing variable fitted separately on either side of the zero threshold using the whole sample and also fully interacted with the Regional seat margin. Regional seat margin is the difference between the seat shares of the parties in the regional government and those of the parties in the opposition in the previous regional election (this variable is demeaned). All columns include a full set of Region and of Alignment $\times$ Region fixed effects. Robust standard errors are in parentheses, clustered at the regional level. $p$-values from wild bootstrapping are in brackets.

transfers increases. The interaction term Alignment $\times$ Regional seat margin captures this effect. Recall that, since we control for Alignment $\times$ Region fixed effects, we are only exploiting the variation over time in regional competition. We present the HLATE estimates for both the RD and the DinD. In the RD case, we present results 


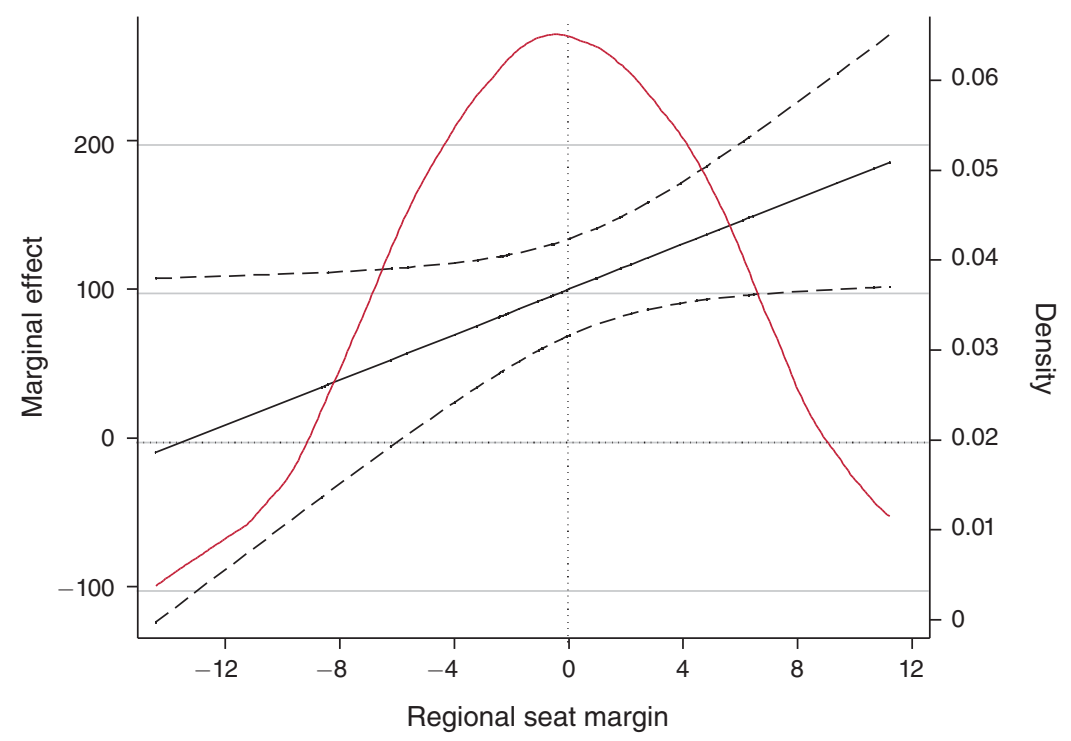

Figure 7. Marginal Alignment Effect

Note: (i) Estimates correspond to the RD estimates (ii) Regional seat margin is the difference between the regional president's party minus the seat share of the opposition parties in the previous state election (this variable is demeaned).

with a local polynomial and different bandwidths (optimal and smaller and larger than the optimal) and with a global polynomial.

In all cases, the coefficient of the interaction variable (Alignment $\times$ Regional seat margin) is statistically significant and positive. The more uncontested a regional election is, the higher the amount of discrimination we observe. The coefficient of the interaction estimated using a local linear regression and the optimal bandwidth is 7.71 euros, which indicates that raising the seat share of the regional government (i.e., decreasing electoral competition) by 1 standard deviation relative to the average translates into a 57 -euro per capita $(=7.44 \times 7.71)$ increase in the treatment effect, which is equivalent to a 52 percent increase in the HLATE $(=57 / 109)$. Figure 7 plots the RD marginal effects against the value of the Regional seat margin. The graph highlights the range of variation in the level of party favoritism: the marginal effect ranges from 0 to 200 euros from one extreme to the other of the $x$-axis, with an average of $109 .{ }^{18}$ In regions with a level of electoral competition 1 standard deviation above the average, aligned mayors receive 166 percent more transfers than unaligned mayors. This effect falls to 52 percent in regions with a level of electoral competition one standard deviation below the average. This heterogeneity may help explain better the magnitude of our local average treatment effect compared to that reported elsewhere.

\footnotetext{
${ }^{18}$ This has been computed as a weighted average of the Alignment $\times$ Region fixed effects and amounts to 109 euro. This value is not very different from the LATE reported in Table 1, which was equal to 102 euro.
} 
Table 3 - Controlling for Time-Varying Covariates. Local RD Estimates

\begin{tabular}{|c|c|c|c|c|c|c|c|}
\hline & (1) & (2) & (3) & (4) & (5) & (6) & (7) \\
\hline Alignment $\times$ Reg. seat marg. & $\begin{array}{l}6.80 \\
(2.90) \\
{[0.032]}\end{array}$ & $\begin{array}{l}7.72 \\
(3.55) \\
{[0.041]}\end{array}$ & $\begin{array}{l}7.53 \\
(3.69) \\
{[0.021]}\end{array}$ & $\begin{array}{l}6.71 \\
(3.80) \\
{[0.114]}\end{array}$ & $\begin{array}{l}8.60 \\
(3.15) \\
{[0.000]}\end{array}$ & $\begin{array}{l}6.56 \\
(3.10) \\
{[0.059]}\end{array}$ & $\begin{array}{l}7.21 \\
(3.01) \\
{[0.021]}\end{array}$ \\
\hline Alignment $\times$ Revenues p.c. & $\begin{array}{c}0.20 \\
(0.07) \\
{[0.210]}\end{array}$ & & & & & & $\begin{array}{l}0.04 \\
(0.18) \\
{[0.861]}\end{array}$ \\
\hline Alignment $\times$ Debt burden & & $\begin{array}{c}-0.71 \\
(5.50) \\
{[0.897]}\end{array}$ & & & & & $\begin{array}{l}0.82 \\
(4.19) \\
{[0.847]}\end{array}$ \\
\hline Alignment $\times$ Population density & & & $\begin{array}{c}-0.01 \\
(0.46) \\
{[0.982]}\end{array}$ & & & & $\begin{array}{c}-1.10 \\
(0.39) \\
{[0.000]}\end{array}$ \\
\hline Alignment $\times$ Tenure in office & & & & $\begin{array}{c}-52.58 \\
(54.97) \\
{[0.477]}\end{array}$ & & & $\begin{array}{c}-17.01 \\
(78.93) \\
{[0.860]}\end{array}$ \\
\hline $\begin{array}{l}\text { Alignment } \\
\quad \times \text { Press circulation p.c. }\end{array}$ & & & & & $\begin{array}{c}-0.77 \\
(0.43) \\
{[0.077]}\end{array}$ & & $\begin{array}{c}-0.32 \\
(0.46) \\
{[0.548]}\end{array}$ \\
\hline $\begin{array}{l}\text { Alignment } \\
\quad \times \text { Percent educated }\end{array}$ & & & & & & $\begin{array}{c}-21.22 \\
(13.21) \\
{[0.160]}\end{array}$ & $\begin{array}{c}-24.89 \\
(20.80) \\
{[0.336]}\end{array}$ \\
\hline Regional seat margin & $\begin{array}{l}0.16 \\
(1.16) \\
{[0.920]}\end{array}$ & $\begin{array}{l}1.26 \\
(1.23) \\
{[0.344]}\end{array}$ & $\begin{array}{l}1.27 \\
(1.23) \\
{[0.336]}\end{array}$ & $\begin{array}{l}1.60 \\
(0.99) \\
{[0.132]}\end{array}$ & $\begin{array}{l}1.17 \\
(1.43) \\
{[0.452]}\end{array}$ & $\begin{array}{l}0.62 \\
(1.09) \\
{[0.592]}\end{array}$ & $\begin{array}{l}1.13 \\
(1.272) \\
{[0.428]}\end{array}$ \\
\hline Observations & 2,576 & 2,576 & 2,576 & 2,576 & 2,576 & 2,576 & 2,576 \\
\hline
\end{tabular}

Notes: Revenues p.c. $=$ current revenues of the regional government per capita (demeaned); Debt burden $=$ regional debt burden (principal + interest) as a share of current revenues (demeaned); Population density = average population density of municipalities in the region (demeaned); Tenure in office = dummy equal to one if the regional incumbent was not in office the previous term; Press circulation p.c. $=$ newspaper copies per 1,000 inhabitants (in the province; demeaned); Percent educated $=$ share of people with primary and secondary education (demeaned). Robust standard errors are in parentheses clustered at the regional level; $p$-values from wild bootstrapping are in brackets. All columns include Region and Alignment $\times$ Region fixed effects. Revenues p.c., Debt burden, Population density, Tenure in office, Press circulation p.c., and Percent educated are included in the regressions fitted separately on either side of the zero threshold and fully interacted with the forcing variable.

The DinD results go in the same direction as the RD estimates. Party favoritism increases with the degree of electoral competition at the regional level. The coefficient of the interaction is also smaller than in the RD, but still quite sizeable (around 3.5).

\section{Time Varying Confounders}

In order to check that the heterogeneous effects we report are in fact due to differences in the degree of electoral competition, we run similar regressions to those in Table 2, but adding interactions between alignment and time-varying confounders (measured at the regional level) that may be correlated with our measure of regional electoral competition (Table 3).

In columns $1-3$, we explore the possible role of the situation of public finances, since it is reasonable to expect that fiscal stress might eventually affect the ability of the regional government to allocate transfers to municipalities. We include interactions with regional revenues per capita (which include revenues coming from 
revenue-sharing, taxes, and intergovernmental grants) and with the debt burden (i.e., debt as a share of current revenues). We also include the average population density of the municipalities in the region, as smaller towns are much more reliant on grants of this kind than are big cities.

In columns 4-6, we report the results when including interactions with variables related to the incentives to discriminate faced by regional politicians. These alternative political mechanisms are not necessarily incompatible with the main story studied in this paper. The first factor is tenure in office (i.e., number of consecutive terms in office). It might be argued that the longer a party stays in office the more time the regional incumbent has to build alliances with local actors and the greater the likelihood of discrimination in the allocation of transfers. Also, informed voters might not be very tolerant of discrimination in transfers between places. To account for this, we include interactions between alignment and the level of press circulation and, also, with the percentage of educated residents. Finally, in the last column, we include all interactions at the same time. The results presented in this table suggest that the introduction of these additional interactions does not have any impact on the electoral competition results. The size of the coefficient and its statistical significance remain unchanged. Therefore, the finding that party favoritism is greater in regions with less competitive elections is robust to the consideration of other plausible influences.

\section{E. Robustness Checks}

In this section, we discuss how our LATE and HLATE results are affected by changes in key aspects of the methodology. First, we show that the results are robust to changes in the way we compute the forcing variable (see column 1 of Table A.14). The results remain the same when using a forcing variable computed assuming that votes are transferred not only from abstention but also from the opposition bloc. 19 The results also remain unchanged when we exclude from the estimation municipalities in which regional or local parties that are not easy to classify are represented on local councils (see columns 2 and 3).

Third, we show the results obtained when using other (more comprehensive) measures of alignment. We report the results for two of these measures (see columns 4 and 5 of Table A.14): Partner alignment, defined as a dummy equal to one when any of the main partners in the coalition at both levels (i.e., not just the president or the mayor) belongs to the same party; and Bloc alignment (i.e., the party of the president and that of the mayor belong to the same ideological bloc). The results for the LATE are similar to those obtained in the main analysis. The HLATE is somewhat smaller in size and less precisely estimated. One possible interpretation of this difference is that when the party of the president and the mayor belong to a different party (although to the same regional coalition), the regional incumbent has

\footnotetext{
${ }^{19}$ The online Appendix includes the plots of the alignment status and of capital transfers against the alternative forcing variable (Figure A.3). These figures show that the size of the discontinuity at the threshold is not sensitive to the assumptions made when computing the forcing variable. The online Appendix also includes the histogram and the McCrary graph of the alternative forcing variable, again with no signs of manipulation (Figure A.4).
} 
less room to reduce the favors made to aligned mayors in the face of an increase in regional competitiveness. Fourth, the results are also robust to restricting the sample only to concurrent elections (column 4).

Fifth, the results are also very similar when we use as a measure of regional electoral competition the seat shares of all the parties in the blocs of the president and the opposition (see Table A.15 in the online Appendix). It appears not to matter whether we use actual or hypothetical coalitions. The measure of regional electoral competition that uses the seat shares of the two main parties does not work particularly well. The problem with this measure is that it misclassifies some situations where although the first party has a clear advantage over the second, it is unlikely to win a majority in the parliament, and so to get enough support to win the regional presidency. Finally, the results regarding the size and statistical significance of the interaction term when we include time varying confounders also remain when using other estimation methods (global RD and DinD), as shown in Table A.16.

\section{F. Alternative Stories}

The results reported clearly indicate that regional governments discriminate in favor of aligned municipalities in the allocation of capital transfers. They also show that the differential amount of transfers allocated to aligned versus unaligned municipalities becomes larger as regional electoral competition drops. The results are statistically significant, quantitatively meaningful, and highly robust. These results are consistent with the predictions of the theoretical model developed in Section I. However, we have to admit that these results also might be consistent with some alternative stories. In this section, we present an additional discussion and evidence that help discard this is actually the case.

Policy Preferences.-Regional governments, which are controlled by different parties, might have different preferences with respect to the policies to be implemented. In addition, regional incumbents might not be perfectly informed about the policy preferences of mayors or might not be able to control the implementation of the projects funded. Imagine a left-wing government that wants to prioritize spending on social services (e.g., building child care facilities) but suspects that right-wing mayors will try to deviate the funds to other goals (e.g., road paving). If this is the case, the regional left-wing government will naturally prefer to allocate more funds to his co-partisans. Moreover, if differences in policy priorities were larger the less competitive elections are (i.e., the regional incumbent feels less compelled to please the median voter), it would be natural to expect that the bias toward co-partisans will grow as regional electoral competition diminishes.

We think that this story is less likely to drive our results. Capital transfers are earmarked to very specific projects. The regional government specifies in the call the policy priorities (e.g., child care facilities, road paving, etc.), so if a municipality asks for funding for a policy that it is not on the list, the chances of getting funds are much lower. Also, the regional government only approves fully specified projects (the municipality has to apply with the actual plan of the new facility and the budget), and only disburses the money once there is proof that the works have been 
completed. This means that the regional government should not worry about the possibility that the transfer is misallocated.

One way to test the validity of the policy preferences argument would be to see whether mayors aligned with the left shift the composition of their expenditure budget toward programs that are more valued by the left as the level of electoral competition increases. We have implemented such a test in the following way. We do not have information regarding the program destination of capital transfers, but we know the program composition of capital expenditures, which is what these transfers are used for. With this information, we can compute the share of capital expenditures allocated to social services, which are services that are supposedly a relative priority of the left. This disaggregated data is only available for the last two terms. During these two terms there is very little regional turnover from left to right or vice versa, meaning that it does not make much sense to try to identify our effect using time variation. Therefore, we show graphically the alignment effect on the share of social spending for Low and High regional competition elections in governments controlled by the Left versus the Right.

The results suggest that the share of expenditures in social services is not discontinuous at the threshold, irrespective of whether the regional government is on the left or on the right or on whether the regional election is competitive or not (see Figure A.5 in the online Appendix). We admit, however, that this piece of evidence might not be totally conclusive, given our reliance on just cross-sectional variation. In addition, if the policy preferences stated in the call do not match those of the municipality, the local government may decide not to submit any proposal. We cannot test this because we do not have information on the applications submitted.

Other Stories. - It might be that the regional incumbent wants to allocate more transfers to local governments controlled by the same party as hers because she expects co-partisans to channel back some of the funds to her. For example, local governments may obtain kickbacks from firms undertaking public works that are then transferred to the regional or national party to help fund its electoral campaigns. Note, however, that it is not clear that such a scenario can be reconciled with our main prediction: lower electoral competition at the regional level reduces campaign finance needs and, hence, the need to use these unorthodox procedures.

It might be, however, that the regional incumbent simply expects to share in the rents generated by the local public works. A lower level of regional electoral competition could foster incentives to behave in this way (see, e.g., Svaleryd and Vlachos 2009), so the main prediction in such a scenario and of our model would be essentially the same. However, several complementary pieces of evidence suggest this is unlikely to be the case. First, we would expect extended periods in office to help in the building of the networks that politicians use to extract these rents, yet we have not found any evidence that tenure in office had any effect on party favoritism (see Table 3). Second, this alternative theory would not necessarily predict that the LATE should be larger than the ATE, which is what the comparison of our RD and DinD results tentatively suggests. Rather, this alternative theory suggests that the local mayors that are best able to extract bribes from public works firms, and to share 
them with comrades at higher levels, are precisely those that won the local election by the greatest margin (and so have no fear of losing the next election if they extract too many rents or if they are caught in a corruption scandal). It could be shown that in this type of model the ATE could in fact be greater than the LATE: transfers would jump at the threshold (a mayor trusts her co-partisans more than the opposition) but continue growing as aligned mayors become more and more popular. We admit, however, that these pieces of evidence are far from conclusive, and that additional work might be needed in order to disentangle this story from ours.

\section{Conclusions}

In this paper, we have examined the way in which competition in regional elections can affect the incentives of regional-level incumbents to discriminate in favor of aligned municipalities. We first present a simple theoretical model in which regional incumbents face a trade-off when deciding how to allocate grants to lower-layer governments. On the one hand, they are concerned about winning the next regional election; on the other, they wish to maximize the number of aligned mayors, which in the long run should help the regional incumbent increase her political capital and win future elections. The main hypothesis derived from this model is that when the regional incumbent performed particularly well in the previous election, and so believes her reelection prospects to be high, she can concentrate her efforts on targeting more resources toward her party comrades.

To test the above hypothesis, we have used capital transfers from regional to local governments in Spain and applied a "fuzzy" RD design that we adapt to a PR electoral system. We find that aligned municipalities, on average, obtain 102 percent more transfers per capita than unaligned municipalities. Such a difference would enable local governments to increase their investments by 21 percent. Moreover, the initial RD design is modified, as in Becker, Egger, and von Ehrlich (2013), in order to obtain local average treatment effects that are heterogeneous across regions with different levels of competition in regional elections. The results suggest that party favoritism is more prevalent when the president's party won the previous election by a large seat margin. In regions with low electoral competition (one standard deviation above the average), aligned mayors receive 166 percent more transfers than unaligned mayors. This effect falls to 52 percent in regions with a higher level of competition. The differences are even larger in the most extreme cases. This result suggests that the level of competition in the elections influences the degree of party favoritism: in places where the elections are largely uncontested, the degree of party favoritism is massive, whereas in places where elections are strongly contested favoritism disappears.

Our results shed light on the mechanisms responsible for the extreme degree of party favoritism in the allocation of transfers. Some complementary sources of evidence suggest that regional incumbents pursue a long-term strategy, seeking to win additional mayoralties and strengthening their power base in order to improve their performance in future elections. The evidence here, however, is merely suggestive and any conclusions should be drawn with extreme care. For the time being, we know that discretionary transfers are subject to extreme levels of party favoritism 
and that electoral competition matters, but more research is required to obtain a full understanding of the motives behind this behavior.

\section{REFERENCES}

Ade, Florian, and Ronny Freier. 2013. "Divided Government versus Incumbency Externality EffectQuasi-experimental Evidence on Multiple Voting Decisions." European Economic Review 64: $1-20$.

Ansolabehere, Stephen, and James M. Snyder, Jr. 2006. "Party Control of State Government and the Distribution of Public Expenditures." Scandinavian Journal of Economics 108 (4): 547-69.

-Arulampalam, Wiji, Sugato Dasgupta, Amrita Dhillon, and Bhaskar Dutta. 2009. "Electoral Goals and Center-Regional Transfers: A Theoretical Model and Empirical Evidence from India." Journal of Development Economics 88 (1): 103-19.

- Becker, Sascha O., Peter H. Egger, and Maximilian von Ehrlich. 2013. "Absorptive Capacity and the Growth and Investment Effects of Regional Transfers: A Regression Discontinuity Design with Heterogeneous Treatment Effects." American Economic Journal: Economic Policy 5 (4): 29-77.

Berry, Christopher R., Barry C. Burden, and William G. Howell. 2010. "The President and the Distribution of Federal Spending." American Political Science Review 104 (4): 783-99.

- Bracco, Emanuele, Ben Lockwood, Francesco Porcelli, and Michaela Redoano. 2015. "Intergovernmental Grants as Signals and the Alignment Effect: Theory and Evidence." Journal of Public Economics 123: 78-91.

Brollo, Fernanda, and Tommaso Nannicini. 2012. "Tying Your Enemy's Hands in Close Races: The Politics of Federal Transfers in Brazil.” American Political Science Review 106 (4): 742-61.

- Burgess, Robin, Remi Jedwab, Edward Miguel, Ameet Morjaria, and Gerard Padró i Miquel. 2015. "The Value of Democracy: Evidence from Road Building in Kenya." American Economic Review 105 (6): 1817-51.

Calonico, Sebastian, Matias D. Cattaneo, and Rocío Titiunik. 2014. "Robust Data-Driven Inference in the Regression-Discontinuity Design.” Stata Journal 14 (4): 909-46.

- Cameron, A. Colin, and Douglas L. Miller. 2015. "A Practitioner's Guide to Cluster-Robust Inference." Journal of Human Resources 50 (2): 317-73.

Colomer, Josep M. 1995. "España y Portugal.” In La política en Europa: Introducción a las instituciones de 15 países, edited by J. M. Colomer. Barcelona: Ariel.

-Cox, Gary W., and Mathew D. McCubbins. 1986. "Electoral Politics as a Redistributive Game." Journal of Politics 48 (2): 370-89.

Diaz-Cayeros, Alberto, Beatriz Magaloni, and Barry R. Weingast. 2003. "Tragic Brilliance: Equilibrium Hegemony and Democratization in Mexico." http://www.academia.edu/5258350/Tragic_Brilliance_Equilibrium_Hegemony_And_Democratization_in_Mexico.

Dixit, Avinash, and John Londregan. 1996. "The Determinants of Success of Special Interests in Redistributive Politics." Journal of Politics 58 (4): 1132-55.

Dreher, Axel, Stephan Klasen, James Raymond Vreeland, and Eric Werker. 2013. "The Costs of Favoritism: Is Politically Driven Aid Less Effective?" Economic Development and Cultural Change 62 (1): 157-91.

-Easterly, William, and Ross Levine. 1997. "Africa's Growth Tragedy: Policies and Ethnic Divisions." Quarterly Journal of Economics 112 (4): 1203-50.

Ferreira, Fernando, and Joseph Gyourko. 2009. "Do Political Parties Matter? Evidence From U.S. Cities." Quarterly Journal of Economics 124 (1): 399-422.

-Fiva, Jon H., Olle Folke, and Rune J. Sørensen. 2018. "The Power of Parties: Evidence from Close Municipal Elections in Norway." Scandinavian Journal of Economics 120 (1): 3-30.

-Fiva, Jon H., and Askill H. Halse. 2016. "Local Favoritism in At-Large Proportional Representation Systems." Journal of Public Economics 143: 15-26.

-Folke, Olle. 2014. "Shades of Brown and Green: Party Effects in Proportional Election Systems." Journal of the European Economic Association 12 (5): 1361-95.

-Fujiwara, Thomas, and Leonard Wantchekon. 2013. "Can Informed Public Deliberation Overcome Clientelism? Experimental Evidence from Benin.” American Economic Journal: Applied Economics 5 (4): 241-55.

Gerber, Elisabeth R., and Daniel J. Hopkins. 2011. "When Mayors Matter: Estimating the Impact of Mayoral Partisanship on City Policy.” American Journal of Political Science 55 (2): 326-39. 
Glaeser, Edward L. 2012. "The Political Risks of Fighting Market Failures: Subversion, Populism and The Government Sponsored Enterprises." National Bureau of Economic Research (NBER) Working Paper 18112.

-Golden, Miriam, and Brian Min. 2013. "Distributive Politics Around the World." Annual Review of Political Science 16: 73-99

-Grossman, Philip J. 1994. "A Political Theory of Intergovernmental Grants." Public Choice 78 (3-4): 295-303.

-Hodler, Roland, and Paul A. Raschky. 2014. "Regional Favoritism." Quarterly Journal of Economics 129 (2): 995-1033.

- Joanis, Marcelin. 2011. "The Road To Power: Partisan Loyalty and the Centralized Provision of Local Infrastructure." Public Choice 146 (1-2): 117-43.

-Larcinese, Valentino, Leonzio Rizzo, and Cecilia Testa. 2006. "Allocating the U.S. Federal Budget to the States: The Impact of the President." Journal of Politics 68 (2): 447-56.

- Lee, David S. 2008. "Randomized Experiments for Non-Random Selection in U.S. House Elections." Journal of Econometrics 142 (2): 675-97.

- Lee, David S., and Thomas Lemieux. 2010. "Regression Discontinuity Designs in Economics." Journal of Economic Literature 48 (2): 281-355.

Lee, David S., Enrico Moretti, and Matthew J. Butler. 2004. "Do Voters Affect or Elect Policies? Evidence from the U.S. House." Quarterly Journal of Economics 119 (3): 807-59.

-Lindbeck, Assar, and Jörgen W. Weibull. 1987. "Balanced-Budget Redistribution as the Outcome of Political Competition." Public Choice 52 (3): 273-97.

-McCrary, Justin. 2008. "Manipulation of the Running Variable in the Regression Discontinuity Design: A Density Test." Journal of Econometrics 142 (2): 698-714.

-Meyersson, Erik. 2014. "Islamic Rule and Empowerment of the Poor and Pious." Econometrica 82 (1): 229-69.

-Migueis, Marco. 2013. "The Effect of Political Alignment on Transfers to Portuguese Municipalities." Economics and Politics 25 (1): 110-33.

Mouritzen, Poul Erik, and James H. Svara. 2002. Leadership at the Apex: Politicians and Administrators in Western Local Governments. Pittsburgh: University of Pittsburgh Press.

-Persico, Nicola, José C. R. Pueblita, and Dan Silverman. 2011. "Factions and Political Competition." Journal of Political Economy 119 (2): 242-88.

-Pettersson-Lidbom, Per. 2008. "Do Parties Matter for Economic Outcomes? A Regression-Discontinuity Approach." Journal of the European Economic Association 6 (5): 1037-56.

-Skjæveland, Asbjørn, and Søren Serritzlew. 2010. "Which Party Gets the Mayoralty? A Multivariate Statistical Investigation of Danish Local Government Formation." Scandinavian Political Studies 33 (2): 189-206.

-Solé-Ollé, Albert, and Pilar Sorribas-Navarro. 2008. "The Effects of Partisan Alignment on the Allocation of Intergovernmental Transfers: Differences-in-differences Estimates for Spain." Journal of Public Economics 92 (12): 2302-19.

-Strom, Kaare. 1989. "Inter-party Competition in Advanced Democracies." Journal of Theoretical Politics 1 (3): 277-300.

-Svaleryd, Helena, and Jonas Vlachos. 2009. "Political Rents in a Non-Corrupt Democracy." Journal of Public Economics 93 (3-4): 355-72.

- Trounstine, Jessica. 2006. "Dominant Regimes and the Demise of Urban Democracy." Journal of Politics 68 (4): 879-93.

-Wright, Gavin. 1974. "The Political Economy of New Deal Spending: An Econometric Analysis." Review of Economics and Statistics 56 (1): 30-38. 